\title{
Genetics May Predict Effectiveness of Tolvaptan in Autosomal Dominant Polycystic Kidney Disease
}

\author{
Akinari Sekine $^{a, b}$ Junichi Hoshino a,b Takuya Fujimaru ${ }^{c}$ Tatsuya Suwabe ${ }^{a, b}$ \\ Hiroki Mizuno $^{a}$ Masahiro Kawada ${ }^{a}$ Rikako Hiramatsu ${ }^{a}$ Eiko Hasegawa ${ }^{a}$ \\ Masayuki Yamanouchia,b Noriko Hayami ${ }^{a}$ Shintaro Mandaic Motoko Chigac

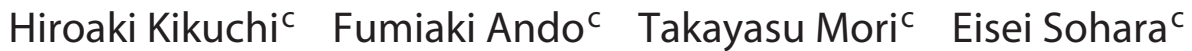 \\ Shinichi Uchidac Naoki Sawa ${ }^{a}$ Kenmei Takaichi ${ }^{a}$ b Yoshifumi Ubara ${ }^{a}$ b \\ aNephrology Center, Toranomon Hospital, Tokyo, Japan; b Okinaka Memorial Institute for Medical Research, \\ Toranomon Hospital, Tokyo, Japan; 'Department of Nephrology, Graduate School of Medical and Dental Sciences, \\ Tokyo Medical and Dental University, Tokyo, Japan
}

\section{Keywords}

Autosomal dominant polycystic kidney disease - Genotype · Polycystic kidney disease 1 . Polycystic kidney disease 2 .

Tolvaptan

\begin{abstract}
Background: Tolvaptan is the only therapeutic drug for autosomal dominant polycystic kidney disease (ADPKD). The influence of mutations in polycystic kidney disease 1 and 2 genes (PKD1 and PKD2) on the treatment effects of tolvaptan is not well documented in the literature. Methods: We retrospectively evaluated the relationship between genotype and the efficacy of tolvaptan in 18 patients with ADPKD who had been treated at Toranomon Hospital and undergone genetic testing between April 2016 and February 2020. Results: The annual change in estimated glomerular filtration rate $(\triangle \mathrm{eGFR} / \mathrm{y})$ from before to after tolvaptan was from a median of -5.5 to $-2.5 \mathrm{~mL} / \mathrm{min} / 1.73 \mathrm{~m}^{2}$ in the PKD1 truncating group, -3.3 to $-2.4 \mathrm{~mL} / \mathrm{min} / 1.73 \mathrm{~m}^{2}$ in the $P K D 1$ non-truncating group, -3.1 to $-1.6 \mathrm{~mL} / \mathrm{min} / 1.73 \mathrm{~m}^{2}$ in the $P K D 2$ group, and -1.9 to $-2.6 \mathrm{~mL} / \mathrm{min} / 1.73 \mathrm{~m}^{2}$ in the group with
\end{abstract}

\begin{tabular}{ll}
\hline karger@karger.com & (C) 2020 The Author(s) \\
www.karger.com/ajn & Published by S. Karger AG, Basel Openger \\
& This article is licensed under the Creative Commons Attribution- \\
Karger & $\begin{array}{l}\text { NonCommercial-NoDerivatives 4.0 International License (CC BY- } \\
\text { NC-ND) (http://www.karger.com/Services/OpenAccessLicense). } \\
\text { Usage and distribution for commercial purposes as well as any dis- } \\
\text { tribution of modified material requires written permission. }\end{array}$
\end{tabular}

no PKD1/2 mutation. The median degrees of improvement of $\triangle \mathrm{eGFR} / \mathrm{y}$ were $2.5(45 \%), 0.4(10 \%), 0.6(28 \%)$, and -0.7 $(-37 \%) \mathrm{mL} / \mathrm{min} / 1.73 \mathrm{~m}^{2}$, respectively. Compared with the group of patients with any PKD1/2 mutation, the group with no $P K D 1 / 2$ mutation showed significantly less improvement in $\Delta$ eGFR/y with tolvaptan $\left(0.6 \mathrm{vs} .-0.7 \mathrm{~mL} / \mathrm{min} / 1.73 \mathrm{~m}^{2}\right.$, respectively; $p=0.01$ ) and significantly less improvement in the annual rate of increase in total kidney volume (TKV) with tolvaptan ( -6.7 vs. $-1.1 \%$, respectively; $p=0.02)$. Conclusion: Patients with ADPKD and no PKD 1/2 mutation showed less improvement in $\triangle \mathrm{eGFR} / \mathrm{y}$ and the annual rate of increase in TKV with tolvaptan. Detecting PKD1/2 mutations may be useful for predicting the effectiveness of tolvaptan.

(c) 2020 The Author(s)

Published by S. Karger AG, Basel

\section{Introduction}

Autosomal dominant polycystic kidney disease (ADPKD) is the most common hereditary cystic kidney disease, affecting 1 in 1,000-2,500 people worldwide [1]. ADPKD has been linked to mutations in 2 genes: polycys- 
tic kidney disease 1 (PKD1) gene (chromosome 16; $16 \mathrm{p} 13.3)$ and polycystic kidney disease 2 (PKD2) gene (chromosome 4; 4q21); the former mutation was found in $78 \%$ of patients and the latter, in 15\% [1]. Approximately $7 \%$ of patients with ADPKD appear not to have a $P K D 1 / 2$ mutation $[2,3]$. Among ADPKD patients, the severity of the effects of these mutations on renal survival was reported to be as follows: $P K D 1$ truncating mutation $>P K D 1$ non-truncating mutation $>$ PKD2 mutation $>$ no $P K D 1$ or $P K D 2$ mutation $[4,5]$.

The only therapeutic drug for patients with ADPKD is tolvaptan, a vasopressin V2-receptor antagonist that slows the rate of decline of the estimated glomerular filtration rate (eGFR). The efficacy of tolvaptan was investigated in the randomized, double-blind, placebo-controlled, multicenter, phase 3 TEMPO 3:4 trial [6] and its long-term extension, TEMPO 4:4 [7], and the efficacy in patients with later-stage ADPKD was investigated in the randomized, double-blind, placebo-controlled, multicenter, phase 3 REPRISE trial [8]. A post hoc analysis of TEMPO 4:4 data found statistically significant treatment effects of tolvaptan in the PKD1 truncating group [7]. However, the treatment effects of tolvaptan in the other groups ( $P K D 1$ non-truncating, $P K D 2$, and no $P K D 1 / 2$ mutation) and the change in clinical course before and after tolvaptan therapy in each group were unclear. Therefore, in the present study, we evaluated the relation between genetic characteristics and treatment effects of tolvaptan by analyzing clinical variables in patients with ADPKD before and after tolvaptan therapy. To our knowledge, this is the first report of the evaluation of the effectiveness of tolvaptan in patients with ADPKD who do not have a $P K D 1 / 2$ mutation.

\section{Materials and Methods}

\section{Patients}

This study included 21 patients with ADPKD who had been treated with tolvaptan at Toranomon Hospital and undergone genetic testing between April 2016 and February 2020. We previously reported on 14 of these patients [9]. Eligibility requirements included a diagnosis of ADPKD according to the protocol of REPRISE trial modified Pei-Ravine criteria [10-12], with an eGFR $>15 \mathrm{~mL} / \mathrm{min} / 1.73 \mathrm{~m}^{2}$, a total kidney volume (TKV) $\geq 750 \mathrm{~mL}$, and a TKV growth rate of $5 \%$ per year or more. All patients were started on $60 \mathrm{mg}$ of tolvaptan in a split-dose regimen $(45 \mathrm{mg}$ in the morning and $15 \mathrm{mg}$ in the evening). The dose was modified according to patients' tolerance; the maximum dose was $120 \mathrm{mg} /$ day.

As an indicator of the decline of renal function, we obtained the eGFR 3-12 times at intervals of a few months (including 1 interval of at least 6 months) both before and after treatment with tolvaptan. The eGFR was calculated with the Japanese eGFR equation
[13]. Then, we used the eGFR data to draw an approximate curve and estimated the decline in renal function from the slope of the curve $(\Delta \mathrm{eGFR} / \mathrm{y})$ for each patient before and after treatment with tolvaptan. As an indicator of the percentage increase in TKV $(\% \Delta \mathrm{TKV} / \mathrm{y})$, we assessed TKV twice before treatment with tolvap$\tan$ (at least 6 months between measurements; median time between measurements: 2 years) and twice after starting treatment with tolvaptan (almost 1.5-3 years between measurements; median time between measurements: 2.3 years). TKV was calculated from CT scans or MR images by the modified ellipse method with the following formula: volume $=\pi / 6 \times$ length $\times$ width $\times$ depth [14] .

Most of the patients were seen at our hospital at least 3 times before and after treatment with tolvaptan, and we were able to collect the required data. However, we were not able to confirm the diachronic data on renal function before tolvaptan therapy in 3 patients and, therefore, excluded them from the study. This study was performed in accordance with the Declaration of Helsinki and was approved by the research Ethics Committees of Toranomon Hospital and Tokyo Medical and Dental University Hospital. Written informed consent was obtained from all patients.

\section{Genetic Analysis}

Genetic analysis was performed with capture-based next-generation sequencing according to the method reported previously $[9,15,16]$. The next-generation sequencing panel provided good coverage of the exonic regions of both $P K D 1$ and $P K D 2$, except for exon 1 of $P K D 1$. This approach detected no mutations of 6 pseudogenes.

\section{Statistical Analysis}

We analyzed the data of the 18 patients with ADPKD and tabulated the clinical characteristics by the type of mutation. Categorical variables were summarized as the number (percentage) and continuous variables as the mean with the standard deviation or median with the interquartile range (IQR). The association between genotype (4 groups: $P K D 1$ truncating, $P K D 1$ non-truncating, $P K D 2$, and no $P K D 1 / 2$ ) and the clinical data was analyzed by the Kruskal-Wallis test; and the association between each of the 4 groups ( $P K D 1$ truncating vs. $P K D 1$ non-truncating, $P K D 1$ truncating vs. $P K D 2, P K D 1$ truncating vs. no $P K D 1 / 2, P K D 1$ non-truncating vs. $P K D 2, P K D 1$ non-truncating vs. no $P K D 1 / 2$, and $P K D 2$ vs. no $P K D 1 / 2)$ or the existence of a $P K D 1 / 2$ mutation and the change in $\Delta \mathrm{eGFR} / \mathrm{y}$ or $\% \Delta \mathrm{TKV} / \mathrm{y}$ before and after tolvaptan therapy were analyzed by the Wilcoxon rank-sum (Mann-Whitney $U$ ) test. For all analyses, $p<0.05$ was taken to indicate statistical significance. Analyses were conducted with STATA ${ }^{\circledR}$ SE version 14.0 (StataCorp, College Station, TX, USA).

\section{Results}

\section{Genetic, Clinical, and Laboratory Characteristics}

On the basis of the probable genetic cause of ADPKD, the 18 patients were classified into the following 4 groups: $P K D 1$ truncating group (4 patients), PKD1 non-truncating group (7 patients), $P K D 2$ group (4 patients), and no $P K D 1 / 2$ group (3 patients). Data on the clinical and laboratory characteristics of these groups at the start of tolvap- 
Table 1. Summary of clinical and laboratory characteristics

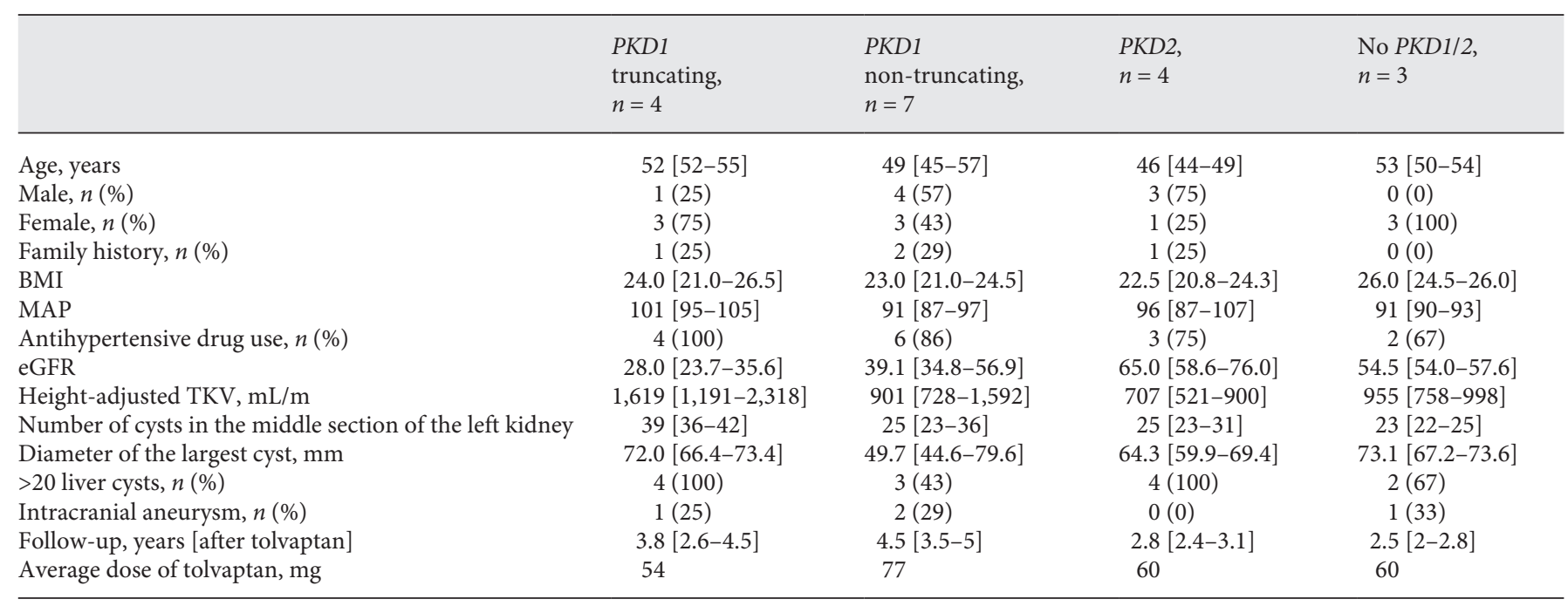

Data are expressed as number (percentage) or median [25th-75th percentiles]. eGFR, estimated glomerular filtration rate; PKD, polycystic kidney disease; MAP, mean arterial pressure; TKV, total kidney volume; PKD1, polycystic kidney disease 1; PKD2, polycystic kidney disease 2.

tan therapy are displayed in Table 1 . The mean dose of tolvaptan was $54 \mathrm{mg}$ in the $P K D 1$ truncating group, $77 \mathrm{mg}$ in the PKD1 non-truncating group, $60 \mathrm{mg}$ in the PKD2 group, and $60 \mathrm{mg}$ in the no $P K D 1 / 2$ group. The dose was reduced in 3 patients ( 2 in the $P K D 1$ truncating group and 1 in the PKD2 group) because of polyuria. No other additional adverse events including liver enzyme elevation, hypernatremia, and volume depletion were observed. The median follow-up period after starting treatment with tolvaptan was 3.8 years (IQR, $2.6-4.5$ years) in the PKD1 truncating group, 4.5 years ( $3.5-5$ years) in the PKD1 nontruncating group, 2.8 years (2.4-3.1 years) in the PKD2 group, and 2.5 years ( $2-2.8$ years) in the no $P K D 1 / 2$ group. We found no significant differences in age, BMI, mean atrial pressure, height-adjusted TKV, the number of cysts (in a middle section of the left kidney), or the follow-up period after starting treatment with tolvaptan between the groups. The patients with $P K D 1$ truncating mutations had significantly decreased eGFR than the other patients (Kruskal-Wallis, $p=0.04$ ). Detailed information on the variants detected in the patients is presented in online suppl. Tables 1-4 (or all online suppl. material, see www. karger.com/doi/10.1159/000509817 f).

\section{Influence of Gene Mutation on the Efficacy of Tolvaptan Therapy}

Figure 1 shows the change in eGFR before and after tolvaptan therapy. We found no changes in variables that may have influenced eGFR, including the use of an angiotensin 2 receptor blocker, before and after tolvaptan therapy. Urine osmolarity, a surrogate of the efficacy of tolvaptan, did not differ between the groups before and after treatment (Table 2). The annual change in eGFR $(\triangle \mathrm{eGFR} / \mathrm{y})$ from before to after tolvaptan therapy was from a median of -5.5 (IQR, -5.7 to -4.4 ) to -2.5 ( -3.1 to $-1.9) \mathrm{mL} / \mathrm{min} / 1.73 \mathrm{~m}^{2}$ in the $P K D 1$ truncating group, $-3.3(-4.6$ to -2.4$)$ to $-2.4(-3.9$ to -2.0$) \mathrm{mL} / \mathrm{min} / 1.73 \mathrm{~m}^{2}$ in the PKD1 non-truncating group, $-3.1(-3.5$ to -2.4$)$ to $-1.6(-2.4$ to -0.5$) \mathrm{mL} / \mathrm{min} / 1.73 \mathrm{~m}^{2}$ in the PKD2 group, and $-1.9(-2.6$ to -1.2$)$ to $-2.6(-3.3$ to -1.8$) \mathrm{mL} / \mathrm{min} / 1.73$ $\mathrm{m}^{2}$ in the no $P K D 1 / 2$ group (Table 2). The median degree of improvement of $\Delta \mathrm{eGFR} / \mathrm{y}$ was 2.5 (45\%) (IQR, 1.8-2.9) $\mathrm{mL} / \mathrm{min} / 1.73 \mathrm{~m}^{2}$ in the PKD1 truncating group, $0.4(10 \%)$ $(-0.2-1.6) \mathrm{mL} / \mathrm{min} / 1.73 \mathrm{~m}^{2}$ in the PKD1 non-truncating group, $0.6(28 \%)(0.5-1.7) \mathrm{mL} / \mathrm{min} / 1.73 \mathrm{~m}^{2}$ in the PKD2 group, and $-0.7(-37 \%)(-0.7$ to -0.6$) \mathrm{mL} / \mathrm{min} / 1.73 \mathrm{~m}^{2}$ in the no $P K D 1 / 2$ group (Fig. 2a). Compared with the $P K D 1$ truncating group, the no $P K D 1 / 2$ group showed significantly less improvement of $\Delta \mathrm{eGFR} / \mathrm{y}$ with tolvaptan $(p=$ 0.03). Compared with the PKD1 non-truncating group, the no $P K D 1 / 2$ group showed significantly less improvement of $\Delta \mathrm{eGFR} / \mathrm{y}$ with tolvaptan $(p=0.04)$. Compared with the PKD2 group, the no PKD1/2 group showed significantly less improvement of $\Delta \mathrm{eGFR} / \mathrm{y}$ with tolvaptan $(p=0.03)$. We found no significant differences in the changes in $\Delta \mathrm{eGFR} / \mathrm{y}$ before and after tolvaptan therapy 


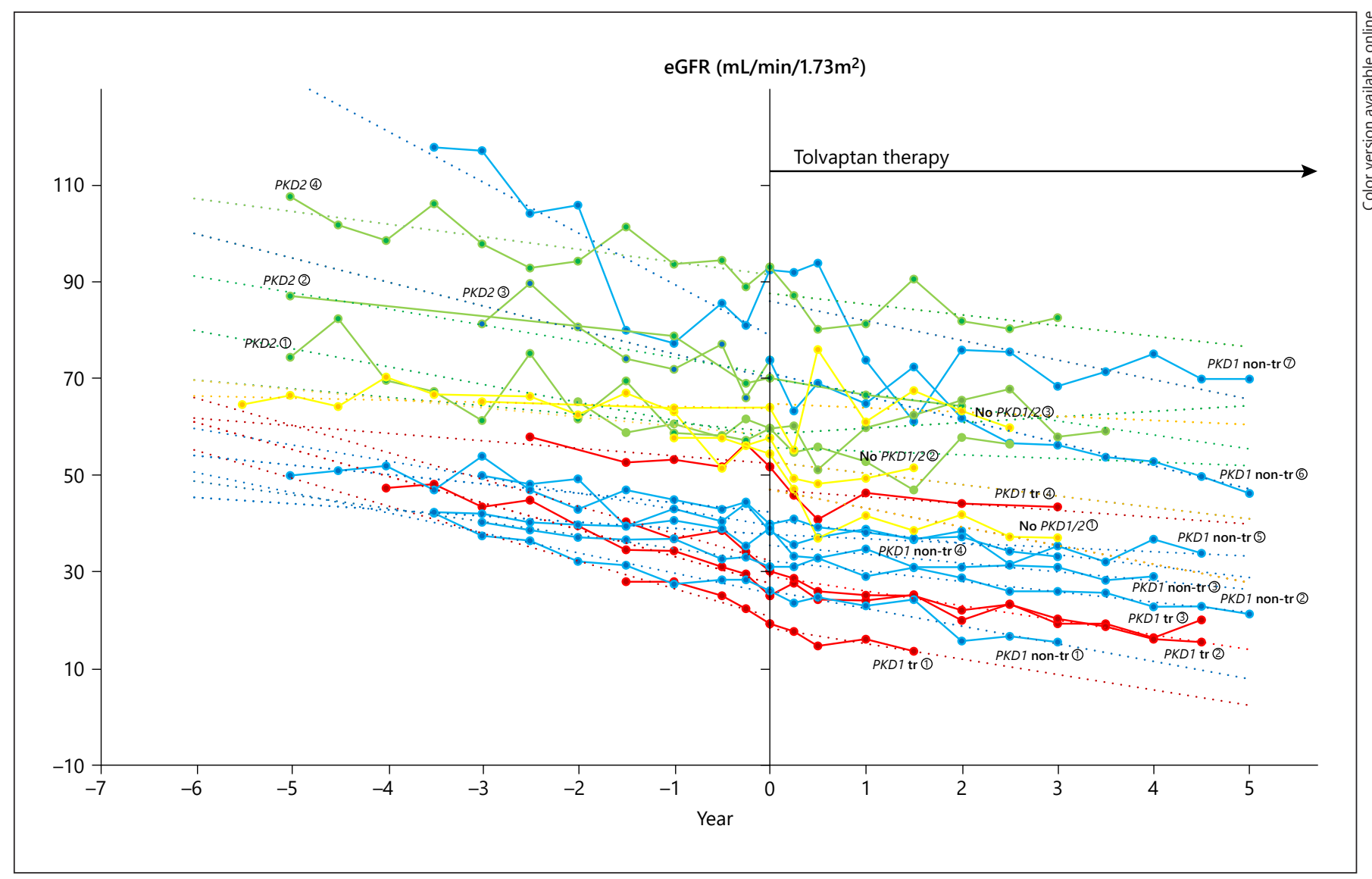

Fig. 1. Summary of changes in eGFR before and after tolvaptan therapy. Red line: $P K D 1$ truncating group ( $n=$ 4); PKD1 tr (1) (4), blue line: PKD1 non-truncating group $(n=7) ; P K D 1$ non-tr (1) (7), green line: PKD2 group $(n=4)$; PKD2 (1) (4), yellow line: no PKD1/PKD2 group $(n=3)$; no $P K D 1 / 2$ (1) (3). eGFR, estimated glomerular filtration rate; $P K D 1$, polycystic kidney disease 1; PKD2, polycystic kidney disease 2 .

Table 2. Summary of clinical and laboratory data before and after tolvaptan therapy

\begin{tabular}{lllll}
\hline & $\begin{array}{l}\text { PKD1 } \\
\text { truncating, } \\
n=4\end{array}$ & $\begin{array}{l}\text { PKD1 } \\
\text { non-truncating, } \\
n=7\end{array}$ & $\begin{array}{l}\text { PKD2, } \\
n=4\end{array}$ & $\begin{array}{l}\text { No PKD1/2, } \\
n=3\end{array}$ \\
\hline Urine osmolarity [before] & $420[410-430]$ & $427[281-560]$ & $519[393-642]$ & $497[441-524]$ \\
Urine osmolarity [after] & $220[205-282]$ & $218[180-236]$ & $183[180-236]$ & $195[168-221]$ \\
$\Delta \mathrm{eGFR} / \mathrm{y}, \mathrm{mL} / \mathrm{min} / 1.73 \mathrm{~m}^{2}$ [before] & $-5.5[-5.7$ to -4.4$]$ & $-3.3[-4.6$ to -2.4$]$ & $-3.1[-3.5$ to -2.4$]$ & $-1.9[-2.6$ to -1.2$]$ \\
$\Delta \mathrm{eGFR} / \mathrm{y}, \mathrm{mL} / \mathrm{min} / 1.73 \mathrm{~m}^{2}$ [after] & $-2.5[-3.1$ to -1.9$]$ & $-2.4[-3.9$ to -2.0$]$ & $-1.6[-2.4$ to -0.5$]$ & $-2.6[-3.3$ to -1.8$]$ \\
$\% \Delta \mathrm{TKV} / \mathrm{y}, \%[$ before $]$ & $5.9[5.6-6.0]$ & $7.1[5.6-7.2]$ & $7.8[7.2-9.0]$ & $5.3[5.2-6.7]$ \\
$\% \Delta \mathrm{TKV} / \mathrm{y}, \%$ after] & $0.2[-3.4-3.1]$ & $0.3[-0.4-2.8]$ & $-1.1[-5.5-3.3]$ & $4.3[3.5-5.7]$ \\
\hline
\end{tabular}

Data are expressed as number (percentage) or median [25th-75th percentiles]. eGFR, estimated glomerular filtration rate; $\Delta \mathrm{eGFR} / \mathrm{y}$, the annual change in eGFR; TKV, total kidney volume; $\% \triangle \mathrm{TKV} / \mathrm{y}$, the annual rate of TKV increase; $P K D 1$, polycystic kidney disease 1 ; $P K D 2$, polycystic kidney disease 2 . 

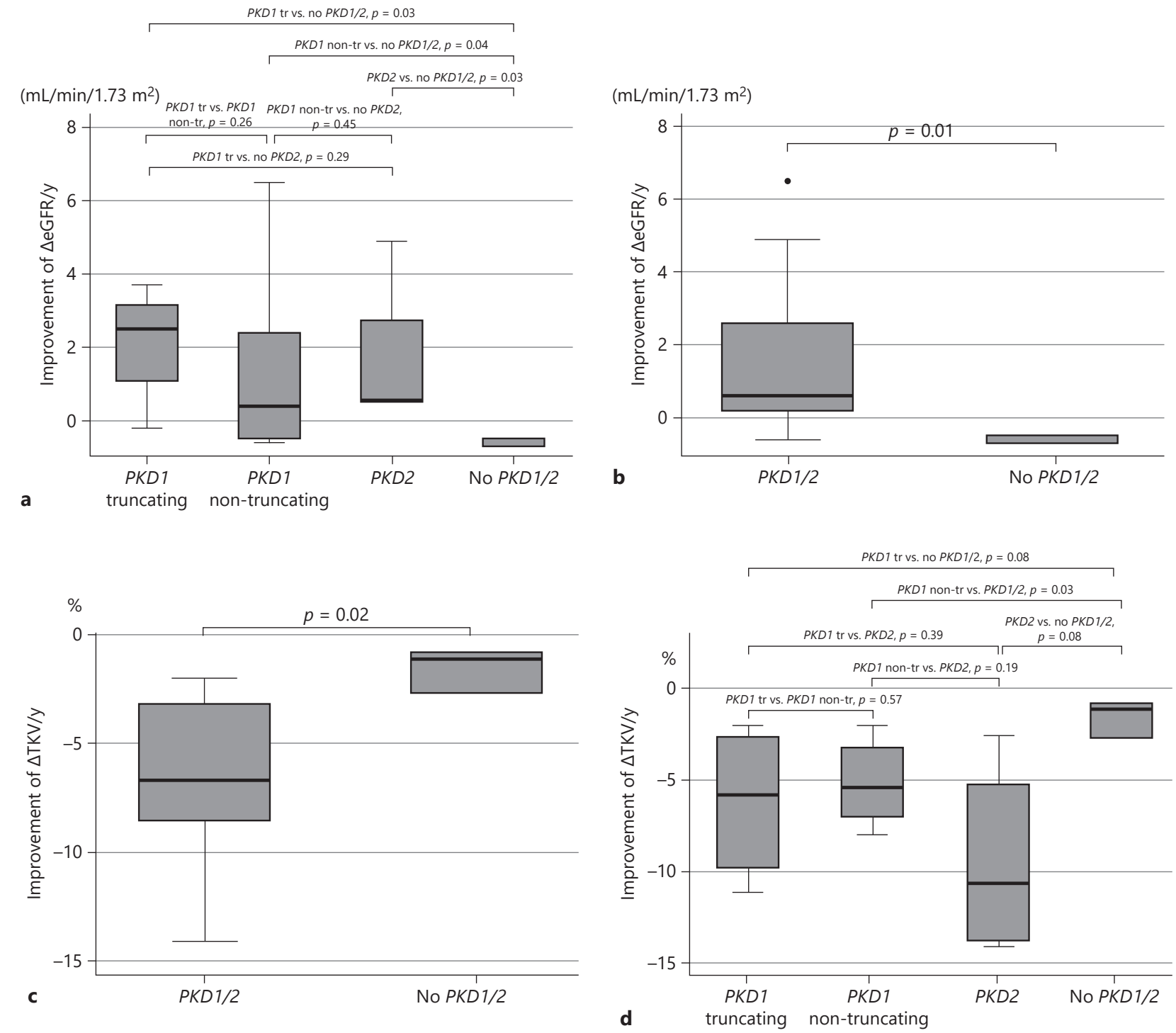

Fig. 2. a Improvement in the annual change in $\Delta \mathrm{eGFR} / \mathrm{y}(\mathrm{mL} /$ $\min / 1.73 \mathrm{~m}^{2}$ ) with tolvaptan therapy by genotype. Improvement of $\Delta \mathrm{eGFR} / \mathrm{y}=(\Delta \mathrm{eGFR} / \mathrm{y}$ after tolvaptan $)-(\Delta \mathrm{eGFR} / \mathrm{y}$ before tolvaptan). $\mathbf{b}$ Improvement in the annual change in $\Delta \mathrm{eGFR} / \mathrm{y}(\mathrm{mL} /$ $\min / 1.73 \mathrm{~m}^{2}$ ) with tolvaptan therapy, $P K D 1 / 2$ group versus no $P K D 1 / 2$ group. Improvement of $\Delta \mathrm{eGFR} / \mathrm{y}=(\Delta \mathrm{eGFR} / \mathrm{y}$ after tolvaptan $)-(\Delta \mathrm{eGFR} / \mathrm{y}$ before tolvaptan). c Percentage improvement in the annual rate of TKV increase $(\% \Delta \mathrm{TKV} / \mathrm{y})$ with tolvaptan therapy, $P K D 1 / 2$ group versus no $P K D 1 / 2$ group. Improve-

between the groups with a $P K D 1$ truncating, $P K D 1$ nontruncating, or $P K D 2$ mutation. The no $P K D 1 / 2$ group showed significantly less improvement of $\Delta \mathrm{eGFR} / \mathrm{y}$ than the group of patients with any $P K D 1 / 2$ mutation ( -0.7 vs. $0.6 \mathrm{~mL} / \mathrm{min} / 1.73 \mathrm{~m}^{2}$, respectively; $p=0.01$, Fig. $2 \mathrm{~b}$ ).

ment of $\% \Delta \mathrm{TKV} / \mathrm{y}=(\% \Delta \mathrm{TKV} / \mathrm{y}$ after tolvaptan $)-(\% \Delta \mathrm{TKV} / \mathrm{y}$ before tolvaptan). d Percentage improvement in the annual rate of $\mathrm{TKV}$ increase $(\% \Delta \mathrm{TKV} / \mathrm{y})$ with tolvaptan therapy by genotype. Improvement of $\% \Delta \mathrm{TKV} / \mathrm{y}=(\% \Delta \mathrm{TKV} / \mathrm{y}$ after tolvap$\tan )-(\% \Delta \mathrm{TKV} / \mathrm{y}$ before tolvaptan). $\Delta \mathrm{eGFR} / \mathrm{y}$, the annual change in estimated glomerular filtration rate; $\% \Delta \mathrm{TKV} / \mathrm{y}$, the annual rate of total kidney volume increase; PKD1, polycystic kidney disease 1; PKD2, polycystic kidney disease 2 .

The annual rate of TKV increase $(\% \Delta \mathrm{TKV} / \mathrm{y}) \mathrm{im}$ proved significantly less in the no $P K D 1 / 2$ group than in the group of patients with any $P K D 1 / 2$ mutation ( -1.1 vs. $-6.7 \%$, respectively; $p=0.02$, Fig. $2 \mathrm{c}$ ). The median $\% \Delta \mathrm{TKV} / \mathrm{y}$ in each of the 4 mutation groups from before 
to after tolvaptan therapy was as follows: $P K D 1$ truncating group, $5.9 \%$ (IQR, $5.6-6.0 \%$ ) to $0.2 \%$ ( -3.4 to $3.1 \%$ ); PKD1 non-truncating group, $7.1 \%(5.6-7.2 \%)$ to $0.3 \%$ ( -0.4 to $2.8 \%)$; in the PKD2 group, $7.8 \%(7.2-9.0 \%)$ to $-1.1 \%$ ( -5.5 to $3.3 \%)$; and in the no $P K D 1 / 2$ group, $5.3 \%$ (5.2-6.7\%) to $4.3 \%$ (3.5-5.7\%) (Table 2). The median degree of improvement of $\% \Delta \mathrm{TKV} / \mathrm{y}$ was $-5.9 \%$ (IQR, -2.9 to $-9.2 \%)$ in the PKD1 truncating group, $-5.4 \%$ ( -3.8 to $-6.9 \%)$ in the PKD1 non-truncating group, $-10.7 \%(-6.6$ to $-13.6 \%)$ in the $P K D 2$ group, and $-1.1 \%(-1.0$ to $-1.9 \%)$ in the no PKD1/2 group (Fig. 2d). We found no significant differences between the groups in the changes in $\% \Delta \mathrm{TKV} / \mathrm{y}$ before and after tolvaptan therapy.

\section{Discussion}

In the current study of 18 patients with ADPKD, $\Delta \mathrm{eGFR} / \mathrm{y}$ and $\% \Delta \mathrm{TKV} / \mathrm{y}$ improved less with tolvaptan therapy in the group without any variants in PKD1 or $P K D 2$ than in the group with a mutation in one of these genes (PKD1 truncating, PKD1 non-truncating, or $P K D 2)$. The efficacy of tolvaptan therapy was investigated in several randomized, double-blind, placebo-controlled, multicenter, phase 3 trials, including the TEMPO 3:4 trial [6]; its long-term extension, the TEMPO 4:4 trial [7]; and the trial in later-stage ADPKD, REPRISE [8]. A post hoc analysis of data from TEMPO 4:4 found statistically significant treatment effects of tolvaptan in the PKD1 truncating group but not in the $P K D 1$ non-truncating or PKD2 group [7]. Unlike the TEMPO 4:4 study, which compared tolvaptan-treated with placebo-treated patients, the current study analyzed the change in $\Delta \mathrm{eGFR} / \mathrm{y}$ and $\% \Delta \mathrm{TKV} / \mathrm{y}$ before to after tolvaptan within patients. For this reason, our results are not directly comparable with those of the TEMPO 4:4 study. However, our study showed efficacy of tolvaptan not only in the PKD1 truncating group but also in the PKD1 non-truncating and $P K D 2$ groups. The important finding of our study is that the patients with ADPKD who had no PKD1/2 mutation showed significantly less improvement of $\Delta \mathrm{eGFR} / \mathrm{y}$ and $\% \Delta \mathrm{TKV} / \mathrm{y}$ before to after tolvaptan therapy.

The vasopressin V2-receptor antagonist tolvaptan was effective in a $P k d 1$-deletion mouse model and $P k d 2$-deletion mouse model of ADPKD [17, 18], so its efficacy may be associated with the PKD1/2 mutations found in patients with ADPKD. At present, PKD1/2 mutations are not considered when administering tolvaptan therapy, but our findings suggest that in the future, physicians may need to test for them. In fact, the ERA-EDTA Working
Group already recommended adding a $P K D 1$ truncating mutation to the criteria for selecting tolvaptan therapy to treat patients with ADPKD [19].

The current study has some limitations. It was a retrospective, single-center study with a small sample size. Furthermore, it may have a selection bias because we included only patients who underwent genetic testing. Genetic testing is not commonly performed in Japan, but it is often performed in patients without an apparent family history. Thus, approximately 200 patients were treated with tolvaptan in our hospital, but genetic testing was performed in only 21 of them. Therefore, our findings need to be confirmed in a large, prospective, multicenter study. Despite these limitations, the study still led to the interesting finding that the efficacy of tolvaptan seems to differ between patients with ADPKD with no PKD1/PKD2 mutation and typical ADPKD patients with a PKD1/PKD2 mutation.

In conclusion, $\Delta \mathrm{eGFR} / \mathrm{y}$ and $\% \Delta \mathrm{TKV} / \mathrm{y}$ improved significantly less with tolvaptan therapy in the group without any detectable PKD1/PKD2 mutation than in the group of patients with a mutation in one of these genes (PKD1 truncating, PKD1 non-truncating, or PKD2). Accordingly, determining whether or not patients with $\mathrm{AD}$ PKD have a $P K D 1 / P K D 2$ mutation may help predict the efficacy of tolvaptan therapy.

\section{Acknowledgement}

The manuscript was checked by a native English-speaking medical editor from Yamada Translation Bureau, Inc. (Tokyo, Japan).

\section{Statement of Ethics}

This study was carried out in accordance with the Declaration of Helsinki and was approved by the research Ethics Committees of Toranomon Hospital and Tokyo Medical and Dental University Hospital. Written informed consent was obtained from all of the patients.

\section{Conflict of Interest Statement}

J.H. has received a research grant from Otsuka Pharmaceutical Co. All other authors have no competing financial interests to declare.

\section{Funding Sources}

This work was supported by a Grant-in-Aid for Scientific Research (JSPS KAKENHI Grant Nos. 18K08227 and 19K17758), a research grant from Otsuka Pharmaceutical Co., and a research 
grant from the Okinaka Memorial Institute to J.H., and by a research grant from the Okinaka Memorial Institute to Y.U. This work was also supported in part by Grants-in-Aid for Scientific Research (S) (25221306) to S.U., Scientific Research (B) (16H05314) to E.S., Challenging Exploratory Research to S.U. (15K15327) and E.S. (16K15467), and Research Activity Start-up (17H06657) to T.M. from the Japan Society for the Promotion of Science; a Health Labor Science Research Grant from the Ministry of Health, Labor and Welfare; and grants from the Salt Science Research Foundation (1422 and 1629) to S.U., the Takeda Science Foundation to E.S., and the Banyu Foundation Research Grant from the Banyu Life Science Foundation International to E.S. None of the funding bodies had any role in the study design, data analysis, decision to publish, or preparation of the manuscript.

\section{Author Contributions}

A.S., J.H., K.T., and Y.U. designed the study; A.S., J.H., T.S., H.M., M.K., R.H., E.H., M.Y., N.H., and N.S. managed the patients and collected clinical data; A.S., J.H., and Y.U. analyzed the genetic and clinical data; T.F., S.M., M.C., H.K., F.A., T.M., E.S., and S.U. analyzed gene mutations; A.S. made the figures and tables; and all authors approved the final version of the manuscript.

\section{References}

1 Cornec-Le Gall E, Alam A, Perrone RD. Autosomal dominant polycystic kidney disease. Lancet. 2019;393(10174):919-35.

2 Audrézet MP, Cornec-Le Gall E, Chen JM, Redon S, Quéré I, Creff J, et al. Autosomal dominant polycystic kidney disease: comprehensive mutation analysis of PKD1 and PKD2 in 700 unrelated patients. Hum Mutat. 2012; 33(8):1239-50

3 Rossetti S, Consugar MB, Chapman AB, Torres VE, Guay-Woodford LM, Grantham JJ, et al. Comprehensive molecular diagnostics in autosomal dominant polycystic kidney disease. J Am Soc Nephrol. 2007;18(7):2143-60.

4 Cornec-Le Gall E, Audrézet MP, Chen JM, Hourmant M, Morin MP, Perrichot R, et al. Type of PKD1 mutation influences renal outcome in ADPKD. J Am Soc Nephrol. 2013; 24(6):1006-13.

5 Hwang YH, Conklin J, Chan W, Roslin NM, Liu J, He N, et al. Refining genotype-phenotype correlation in autosomal dominant polycystic kidney disease. J Am Soc Nephrol. 2016; 27(6):1861-8.

6 Torres VE, Chapman AB, Devuyst O, Gansevoort RT, Grantham JJ, Higashihara E, et al. Tolvaptan in patients with autosomal dominant polycystic kidney disease. N Engl J Med. 2012;367(25):2407-18.

7 Torres VE, Chapman AB, Devuyst O, Gansevoort RT, Perrone RD, Dandurand A, et al. Multicenter, open-label, extension trial to evaluate the long-term efficacy and safety of early versus delayed treatment with tolvaptan in autosomal dominant polycystic kidney disease: the TEMPO 4:4 trial. Nephrol Dial Transplant. 2018;33:477-89.
8 Torres VE, Chapman AB, Devuyst O, Gansevoort RT, Perrone RD, Koch G, et al. Tolvaptan in later-stage autosomal dominant polycystic kidney disease. N Engl J Med. 2017; 377(20):1930-42

9 Sekine A, Fujimaru T, Hoshino J, Suwabe T, Oguro M, Mizuno H, et al. Genotype-clinical correlations in polycystic kidney disease with no apparent family history. Am J Nephrol. 2019;49(3):233-40.

10 Torres VE, Devuyst O, Chapman AB, Gansevoort RT, Perrone RD, Ouyang J, et al. Rationale and design of a clinical trial investigating tolvaptan safety and efficacy in autosomal dominant polycystic kidney disease. Am J Nephrol. 2017;45(3):257-66.

11 Pei Y, Obaji J, Dupuis A, Paterson AD, Magistroni R, Dicks E, et al. Unified criteria for ultrasonographic diagnosis of ADPKD. J Am Soc Nephrol. 2009;20(1):205-12.

12 Ravine D, Gibson RN, Walker RG, Sheffield LJ, Kincaid-Smith P, Danks DM. Evaluation of ultrasonographic diagnostic criteria for autosomal dominant polycystic kidney disease 1. Lancet. 1994;343(8901):824-7.

13 Matsuo S, Imai E, Horio M, Yasuda Y, Tomita K, Nitta K, et al. Revised equations for estimated GFR from serum creatinine in Japan. Am J Kidney Dis. 2009;53(6):982-92.

14 Cadnapaphornchai MA, McFann K, Strain JD, Masoumi A, Schrier RW. Prospective change in renal volume and function in children with ADPKD. Clin J Am Soc Nephrol. 2009;4(4):820-9.
15 Fujimaru T, Mori T, Sekine A, Mandai S, Chiga $\mathrm{M}$, Kikuchi $\mathrm{H}$, et al. Kidney enlargement and multiple liver cyst formation implicate mutations in $\mathrm{PKD} 1 / 2$ in adult sporadic polycystic kidney disease. Clin Genet. 2018;94(1): 125-31.

16 Mori T, Hosomichi K, Chiga M, Mandai S, Nakaoka H, Sohara E, et al. Comprehensive genetic testing approach for major inherited kidney diseases, using next-generation sequencing with a custom panel. Clin Exp Nephrol. 2017;21(1):63-75.

17 Torres VE, Wang X, Qian Q, Somlo S, Harris PC, Gattone VH 2nd. Effective treatment of an orthologous model of autosomal dominant polycystic kidney disease. Nat Med. 2004;10(4):363-4.

18 Meijer E, Gansevoort RT, de Jong PE, van der Wal AM, Leonhard WN, de Krey SR, et al. Therapeutic potential of vasopressin V2 receptor antagonist in a mouse model for autosomal dominant polycystic kidney disease: optimal timing and dosing of the drug. Nephrol Dial Transplant. 2011;26(8):244553.

19 Gansevoort RT, Arici M, Benzing T, Birn H, Capasso G, Covic A, et al. Recommendations for the use of tolvaptan in autosomal dominant polycystic kidney disease: a position statement on behalf of the ERA-EDTA working groups on inherited kidney disorders and european renal best practice. Nephrol Dial Transplant. 2016;31(3):33748. 